\title{
Lung health in the Eastern Mediterranean Region: the need to end designated smoking areas in public places
}

Fatimah El-Awa, ${ }^{1}$ Mohamed Awad Tageldin, ${ }^{2}$ Vinayak Prasad, ${ }^{3}$ Ahmad Al-Mulla, ${ }^{4}$ Gholamreza Heydari ${ }^{5}$ and Raouf Alebshehy ${ }^{6}$

${ }^{1}$ Regional Advisor, Tobacco Free Initiative Unit, Department for Noncommunicable Diseases and Mental Health, World Health Organization Regional Office for the Eastern Mediterranean, Cairo, Egypt. ${ }^{2}$ Professor, Faculty of Medicine, Ain Shams University, Cairo, Egypt. ${ }^{3}$ Programme Manager, Department for Prevention of Noncommunicable Diseases, World Health Organization, Geneva, Switzerland. ${ }^{4}$ Director, WHO Collaborating Centre for Treating Tobacco Dependence, Tobacco Control Center, Pulmonary Section, Medical Department, Hamad Medical Corporation, Doha, Qatar. ${ }^{5}$ Tobacco Prevention and Control Research Center, National Research Institute of TB and Lung Diseases, Shahid Beheshti University of Medical Sciences, Tehran, Islamic Republic of Iran. ${ }^{6}$ Regional Consultant, Tobacco Free Initiative Unit, Department for Noncommunicable Diseases and Mental Health, World Health Organization Regional Office for the Eastern Mediterranean, Cairo, Egypt. (Correspondence to: Raouf Alebshehy: alebshehyr@who.int).

Citation: El-Awa F; Tageldin MA; Prasad V; Al-Mulla A; Heydari G; Alebshehy R. Lung health in the Eastern Mediterranean Region: the need to end designated smoking areas in public places. East Mediterr Health J. 2019;25(5):297-298. https://doi.org/10.26719/2019.25.5.297

Copyright (C) World Health Organization (WHO) 2019. Some rights reserved. This work is available under the CC BY-NC-SA 3.0 IGO license (https:// creativecommons.org/licenses/by-nc-sa/3.0/igo).

Tobacco use is a fatal habit that causes harm to almost all organs of the human body (1) and kills up to half of its users (2). Studies have shown that tobacco contains a poisonous mix of more than 7000 chemicals (3) that have major consequences, including heart attacks and strokes (3), and are considered major risk factors for many types of cancer (4) and the leading cause of lung cancer (1). Moreover, tobacco use dramatically affects the respiratory system, damaging its airways and alveoli, and leading to chronic obstructive lung diseases ${ }^{1}$ including emphysema and chronic bronchitis (1).

Available evidence in the Eastern Mediterranean Region (EMR) strongly links tobacco use with lung diseases, which equally affect male and female tobacco smokers in the Region (5,6). For example, in asthmatic patients it is found that tobacco use can trigger repetitive attacks of asthma with increasing severity (1) and can be aggravated by direct and second-hand smoking (2). It has been estimated that 7 million people die annually from tobacco use, of whom approximately $13 \%$ are nonsmokers exposed to second-hand smoke (2).

The World Health Organization Framework Convention on Tobacco Control (WHO/FCTC) has already addressed this particular issue in Article 8 and in its guidelines and has requested full protection of the public from second-hand smoke by ending tobacco use in public places (7), which is yet to be implemented adequately in the Eastern Mediterranean Region (6). In addition, WHO has recommended implementing smoke-free public places in parallel with other tobacco control measures such as tobacco control dependency treatment (Article 14 of FCTC) (8), which are fundamental to maximize the positive impact on public health (9).

Tobacco use is a global epidemic of 1.1 billion smokers with 4 out of 5 smokers living in low- and middle-income countries (2). The most recent tobacco trends report, published by WHO in 2018, expects tobacco use to decline in most regions except for the EMR, which by contrast will witness an increase from a prevalence of $18.1 \%$ in 2015 to $18.7 \%$ in 2025 (10). The previously estimated 82 million smokers in the EMR in 2015 are projected to reach 107 million in 2025 (10), and clearly indicates that the Region is lagging in achieving the targeted prevalence of $12.6 \%$ by 2025 (10)

Indeed, smoking prevalence in some countries of the EMR has reached alarming numbers - up to $50 \%$ of adult males, $34 \%$ of adult females, $34 \%$ of young males and $17 \%$ of young females (11). Additionally, the Region has the highest global prevalence of water-pipe use with an increasing trend among young people (12); research indicates a water-pipe use prevalence of $28.6 \%$ among young people and $31.9 \%$ among adults (13) and that lung hazards from water-pipe smoking are more serious than cigarette use $(14,15)$, especially among young adults (16). Moreover, the current tobacco use epidemic not only includes cigarette-use but also water-pipe use, electronic cigarettes and heated tobacco products, which have all been identified as contributing factors to the deterioration of lung health $(17,18)$.

On 31 May 2019, the World No Tobacco Day (WNTD) theme focuses on "tobacco and lung health" (19). On this occasion, WHO is taking the opportunity to emphasize that lung health improves by reduction of both tobacco use and exposure to second-hand smoke (19). It is now well documented that the risk of lung cancer falls by $50 \%$ following 10 years of quitting tobacco (19).

This year's WNTD theme provides an opportunity to empower countries with scientific evidence and awareness tools in order to fully implement Article 8 of the WHO/FCTC on protecting people from second-hand smoke and eliminating tobacco use from indoor public spaces (7).

Currently, the EMR is suffering from the phenomenon of designated smoking areas in public places; very few countries in the Region have adhered to Article 8 of the WHO/FCTC and its guidelines (11). It

Chronic Obstructive Pulmonary Disease (COPD) is a chronic progressive disease with a decline in lung functions and recurrent exacerbation, leading to progressive shortness of breath and exercise intolerance, which negatively reflects on the social life of patients, their families and the community. 
is hoped that WNTD, with its focus on lung health, can contribute to ending the designation of smoking areas in public places, and that decision-makers are made aware of the evidence that even the inclusion of ventilation systems do not reduce the potential for harm (7). In fact, ventilation systems circulate smoke to nonsmoking areas, thereby contributing to increased mortality and morbidity due to second-hand smoke exposure $(20,21)$.
Globally we are seeing best practices put in place to liberate all public places from tobacco use (22), and yet in the EMR we are still struggling to just eliminate tobacco use from indoor public places. There has to be substantial movement by governments and relevant authorities on this issue if there is to be any credible progress on reducing mortality and morbidity related to tobacco use in the Region. The WNTD for 2019 is a wake-up for this Region to take bold steps now and end designated smoking areas.

\section{References}

1. Centers for Disease Control and Prevention. Health effects of cigarette smoking. Atlanta: CDC; 2018 (https://www.cdc.gov/ tobacco/data_statistics/fact_sheets/health_effects/effects_cig_smoking/index.htm).

2. World Health Organization. Tobacco. Geneva: World Health Organization; 2018 (https://www.who.int/en/news-room/fact-sheets/ detail/tobacco).

3. Centers for Disease Control and Prevention. A report of the surgeon general: How Tobacco smoke Causes Disease. Atlanta: CDC; 2010 (https://www.cdc.gov/tobacco/data_statistics/sgr/2010/consumer_booklet/pdfs/consumer.pdf).

4. American Cancer Society. Study: Smoking causes almost half of deaths from 12 cancer types. Atlanta: ACSC; 2015 (https://www. cancer.org/latest-news/study-smoking-causes-almost-half-of-deaths-from-12-cancer-types.html).

5. Al Ghobain M. The prevalence of chronic obstructive pulmonary disease in Saudi Arabia: Where do we stand? Ann Thorac Med. 185:(4)6;2011.

6. Ahmed R, Robinson R, Mortimer K. (2017). The epidemiology of noncommunicable respiratory disease in sub-Saharan Africa, the Middle East, and North Africa. Malawi Med J. 203:(2)29;2017.

7. World Health Organization Framework Convention for Tobacco Control. Guidelines for implementation of Article 8. Geneva: World Health Organization; 2007 (https://www.who.int/fctc/guidelines/adopted/article_8/en/).

8. World Health Organization Framework Convention on Tobacco Control. Guidelines for implementation of Article 14. Geneva: World Health Organizations; 2010 (https://www.who.int/fctc/guidelines/adopted/article_14/en/).

9. Heydair G, Zaatari G, Al-Lawati J, El-Awa F, Fouad H. MPOWER, needs and challenges: trends in the implementation of the WHO FCTC in the Eastern Mediterranean Region. East Mediterr Health J. 71-63:(1)24;2018 (https://doi.org/2018.24.1.63/10.26719).

10. World Health Organization. WHO global report on trends in prevalence of tobacco smoking 2) 2025-20oond edition). Geneva: World Health Organization; 2018 (https://www.who.int/tobacco/publications/surveillance/trends-tobacco-smoking-secondedition/en/).

11. World Health Organization. WHO report on the global tobacco epidemic 2017. Geneva: World Health Organization; 2017 (https:// www.who.int/tobacco/global_report/en/).

12. World Health Organization. Control and prevention of waterpipe tobacco products Report. Geneva: World Health Organization; 2016 (https://www.who.int/fctc/cop/cop7/FCTC_COP_10_7_EN.pdf).

13. Jawad M. The prevalence and trends of waterpipe tobacco smoking: A systematic review. PloS One 2)13;2018) eo192191.

14. Boskabady MH, Mahmoudinia M, Eslamizade MJ, Boskabady M, Shakeri MT, Heydari GR. The prevalence of smoking among the population in the city of Mashhad (north east of Iran) and pulmonary function tests among smokers. Pneumonol Alergol Pol. 5-21(1)79;2011.

15. Ramezankhani A, Zaboli FS, Zarghi A, Masjedi MR, Heydari GR. Smoking habits of adolescent students in Tehran. Tanaffos. 42-33:(2)9;2010.

16. Boskabady MH, Mahmoodinia M, Boskabady M, Heydari GR. Pulmonary function tests and respiratory symptoms among smokers in the city of Mashhad (North East of Iran). Rev Port Pneumol. 2011 Sep-Oct;204-199:(5)17.

17. Hessami Z, Masjedi M, Ghahremani R, Kazempour M, Emami, H. Evaluation of the prevalence of waterpipe tobacco smoking and its related factors in Tehran, Islamic Republic of Iran. East Mediterr Health J. 99-94:(2)23;2017.

18. Sayiner A, Alzaabi A, Obeidat N, Nejjari C, Beji M, Uzaslan E, et al. (2012). Attitudes and beliefs about COPD: Data from the BREATHE study. Respir Med. 106;2012:S-60S74.

19. World Health Organization. World No Tobacco Day. Geneva: World Health Organization; 2019 (https://www.who.int/news-room/ events/detail/31/05/2019/default-calendar/world-no-tobacco-day).

20. Cains T. Designated «no smoking» areas provide from partial to no protection from environmental tobacco smoke. Tob Control. 22-17:(1)13;2004.

21. Matt G, Quintana P, Fortmann A, Zakarian J, Galaviz V, Chatfield D, et al. Thirdhand smoke and exposure in California hotels: non-smoking rooms fail to protect non-smoking hotel guests from tobacco smoke exposure. Tob Control. 272-264:(3)23;2013.

22. The Cancer Council. Tobacco in Australia. Smoking bans in outdoor areas. Victoria: The Cancer Council; 2019 (https://www. tobaccoinaustralia.org.au/chapter-15-smokefree-environment/-5-15outdoor-areas). 